\title{
Mother's Influence On Cognitive Development: A Cultural Perspective.
}

\author{
Nonofo Losike- Sedimo \\ University of Botswana
}

\begin{abstract}
Parenting in most African cultures is practiced by both the nuclear family and the extended one. This is still a virtue in Setswana culture. This case study observed how a mother's role in Botswana' culture influence children's cognitive development expressed in her daily practices. The objective was to establish how mother's parenting style relates to cognitive development. The study analyses the experiences of a sixyear-old Botswana boy against this background. The mothers' role was isolated notwithstanding the fact that children grow up in multiple contexts of a given culture. Every culture is characterized, and distinguished from other cultures, by fundamental believes which are deep rooted and controls how children should feel, think, act, reflect, search for meaning, socialize and appropriately function as members of the society The study is guided by Bronfenbrenner's Ecological theory which afforded the researcher to define which context will be considered for the study. It takes place in a rural undeveloped remote village in Botswana where a young boy of six years and his mother were studied under the five contexts of Bronfenbrenner's theory. The research design was a case study. Results revealed that mothers and fathers share some childrearing attributes and effects, and differ in unique ways that influence different domains of child development. And that family members subscribed to unique conventions of culture and followed cultural scripts of raising children morally. It was concluded that cognitive development is influenced by the mother's cultural roles. And that cultural contexts are multi-layered at home, in the neighbourhood, community and society. The results suggests that cognitive development is culture specific.
\end{abstract}

Keywords: cultural mother and child, father and child, relationship quality, cognitive development.

Learning and cognition develop rapidly within the first six years of life (Stevenson \& Crnic, (2015; Fenning, et al. 2014; Crnic et al., 2009; Bandura, 1969;Piaget,1926, 1924)

The central aim of this research was to study how mothering practices in Botswana influence children's cognitive development. It focuses on age six of the children. The effects of maternal deprivation on cognitive development are well known .(Stevenson \& Crnic, 2015; Crnic et al., 2009, Bandura, 1969), but the mechanisms of these effects still lack a satisfactory explanation. Most studies concentrate on children's negative behaviour and home background,(Fenning, et al. 2014). The study seeks to investigate how culture affect matters of cognition. Learning and cognition develop rapidly within the first six years of life (Piaget, 1924,1926). The researcher concentrated her attention on this age, focusing on learning as much as possible about mothering in the cultural context of Botswana and its role in cognitive development. From reviewed literature two areas have contributed to the conceptualisation of the study problem.

These were;

Studies of mother - child interaction. Studies comparing motherhood from different cultures. The literature review pointed to an important connection between a mother or mother figure and the child's behaviour and mental health. For instance the behavioural state of an infant 
was observed to influence the course of the mother in the mother child interactions. Jocson, Alampay \& Lansford, (2012). The act of speaking or vocalization and facial expression were cited as critical components of social communication that accompany certain phases of learning (Schaffer, 1977)

The cognitive development benefits from the mother's love, caring, guidance and reinforcement and other behaviour modification techniques were also elaborated on by many studies (Bornstein,2010;Paris, 2000). On another level studies on mental health observed that negative paternal behaviour is predicted by earlier child behaviour while negative maternal behaviours predicts child difficulties. Furthermore the same study also reported that parents who had high quality relationship with their parents during childhood were not at risk for mental illness but had excellent mental health. Cognitive development is a mental activity, that is why psychology researchers take interest in mental health. In Botswana, Shapera,(1970) observed the importance of the mothering role of nurturing a child. Indeed mothers are more possessive of child development driving seat. A mother is like a protective hen caring for its chicks. The mother is the safe haven or source of security feelings, a guide, a coach, a judge, a role model, and a mentor and source of attachment and sense of belonging.

The mothering responsibilities and skills go a long way in socializing the child and insuring his or her intellectual development is appropriate for their cultural roles in the home, community and society at large. Losike - Sedimo, (2015).One great African American mother expressed the role of a mother as follows: "I believe the children are our future, teach them well and let them lead the way, show them all the beauty they possess inside, give them a sense of pride to make it easier." (Huston, 1986). These words speak to the daily chores of a Motswana mother. The same concept of nurturing the child's potential or protecting the future by mothers was observed in other cultures. In a study entitled growing up our way Allara, Hawting \& Harrison,(2011) observed the mothers' cultural way of directing the child's future by making her to grow up the cultural way.

This study analyses the experiences of a six-year-old Botswana boy within the cultural concepts of child rearing. Literature also revealed that Parents in different cultures typically harbour unique beliefs about their parenting as well as about children. In a study of seven cultures (Argentina, Belgium, France, Israel, Italy, Japan, and the United States), mothers evaluated their competence, satisfaction, investment, and role balance in parenting attributed their successes and failures in parenting to ability, effort, mood, parenting task difficulty, or child behaviour. It emerged that that the differences in mothering practice were embedded in their cultures. recorded that the mother's culture affect the children's cognitive development. It is against this background that this study was perceived.

\section{BACKGROUND TO THE STUDY}

Family systems theory suggests that the family is a complex, dynamic, and integrated whole, in which each member influences and is influenced by all other members (Minuchin, 1988; O'Brien, 2005). This is true in Botswana. The context and social background of the study is based on the daily experiences of infants and young children that they undergo at home, in school, and child care in relation to cognitive development. Rosenthal and Zimmerman, (1978) stated that mothers daily experiences are vital to cognitive development. The influences of such experiences depend on the composition of the family in many important ways.

In Botswana the majority of the children under six years live in breadwinner, homemaker families in the rural and sometimes remote and rural villages. The family may have two biological parents or one but there is always a mother figure who takes care of the child on full 
time basis. The mother figure is also the homemaker. The breadwinner typically works in the farm or homestead outside the home In a few islands of affluence sometimes both mother and father are working, in such a situation a caregiver is employed. The mother would therefore spend less time with the child than the caregiver. Such mothers account for less than $10 \%$ of the population, (Botswana Statistics,2010)

\section{Statement of the problem}

The problem addressed in this article is examining the possible cultural ways and factors that can promote cognitive development through the mother's care and interactions

\section{Purpose}

The purpose of this study is to find out the relationship of a mother's cultural role and children's cognitive development

\section{THE OBJECTIVE OF THE STUDY}

The objective of this research is to study how mothering practices in Botswana influence children's cognitive development. The role of the mother's impact on cognitive development is visible but what is not known is how it impacts on cognitive development (Stevenson \& Crnic, 2015; Crnic et al., 2009, Bandura, 1969). The contrivances of the how such development comes about lack scientific information. There is a gap in literature on how culture promotes cognition. This article will contribute to that area. More visibility in literature about mothering and cognition in the African context is needed. Bornstein (2013) stated that it is imperative to study non-western culture regarding parents and cognition. Educators and psychological counsellors in Botswana and elsewhere can benefit from the results of the study. Therefore this study will contribute to the knowledge of culture and cognition.

\section{Rationale}

There is a call in the literature for more studies on cognitive development and mental health for different cultures. One author stated "after approximately a century of psychological studies, with considerable attention paid to parenting and child mental health, still too little is known about the beliefs and behaviours, life circumstances and experiences, of children or their parents in non-Western cultures. (Bornstein, 2010). Family and culture impacts on cognitive development of children. The objective of this study is to investigate the relationship of mother's cultural role of raising children with the cognitive development of children. Literature critiques traditional research in this field for the tendency to describe constructs, structures, functions, and processes in accordance with ideals appropriate to Western, educated, industrialized, rich, and democratic societies. For example, Patel and Sumathipala surveyed leading psychiatry journals and found that only " $6 \%$ of the literature were published from regions of the world that account for over $90 \%$ of global population" (Patel \& Sumathipala, (2001).So more voices need to be heard from many different cultures to share what pertains in them. This study is an attempt to be one of those voices.

\section{Significance}

The study will provide information on the role of culture in mental or cognitive development. The study will provide information on a mother's cultural role's impact on cognitive development and how it works in Botswana.

\section{Theoretical framework}

\section{LITERATURE REVIEW}

Urie Bronfenbrenner (1979) developed the ecological systems theory to explain how everything in a child and the child's environment affects his growth and development. 
Bronfenbrenner's bio-ecological systems theory considers the influences on a child's development within the context of the complex system of relationships that form his or her environment. The theory suggests that a child's development is a product of a variety of critical dimensions included in contexts, processes, time, and the individual's personal attributes. Drawing upon the pioneering work of social psychologist Kurt Lewin, Bronfenbrenner's theory emphasizes the "joint function" that personal attributes and environmental characteristics have in influencing an individual's development. In brief, Bronfenbrenner's theory defines the construct of development and the multi-system layers of the environment that influences child development. Culture is one lens that people see and interpret their life actions with. It is a major context that situates life experiences. (Berk,2002)

Furthermore, Bronfenbrenner describes the nature of the processes within the environment that influence development.(see the diagram). As such the theory goes beyond providing a framework for identifying and conceptualizing the multi-system factors that influence development. It considers an individual's topology, his or her setting and the way in which the individual and external forces interplay to influence development. It most importantly, attempts to underscore processes and the dynamics of these processes that might influence development. It is these dynamics that the study seek to observe in the interactions of mother and child. The following section explains the how of the child, mother and external forces interplay within various contexts as a child grows according Bronfenbrenner circles of environmental contexts.

\section{The microsystem}

This is the layer closest to the child and the only one that contains the structures with which the child has direct contact. The microsystem encompasses the relationships and interactions a child has with her immediate surroundings. Structures in the microsystem include family, school, neighbourhood, or childcare environments. At this level, relationships have impact in two directions both away from the child and toward the child. For example, a child's parents may affect his beliefs and behaviour however, the child also affects the behaviour and beliefs of the parent. Bronfenbrenner calls these bi-directional influences, and he shows how they occur among all levels of environment. The interaction of structures within a layer and interactions of structures between layers is key to this theory. At the microsystem level, bi-directional influences are strongest and have the greatest impact on the child. However, interactions at outer levels can still impact the inner structures.(Berk, 2009)

\section{The Mesosystem}

In this circle two microsystems begin to work together, it could be teacher and parent working together to educate a child, it happens through the mesosystem. The mesosystem could include experiences at home related to experiences at school, or experiences at school related to experiences at church. Much like the microsystem, the individual is not simply observing the things happening to them, but are playing an active role in helping create the experiences they want.

\section{The Exosystem}

This layer defines the larger social system in which the child does not function directly. The structures in this layer impact the child's development by interacting with some structure in her microsystem. Parent workplace schedules or community-based family resources are examples. The child may not be directly involved at this level, but he does feel the positive or negative force involved with the interaction with his own system.(Berk, 2004) 


\section{The Macrosystems}

This layer may be considered the outermost layer in the child's environment. While not being a specific framework, this layer is comprised of cultural values, customs, and laws (Berk, 2000). The effects of larger principles defined by the macrosystems have a cascading influence throughout the interactions of all other layers. For example, if it is the belief of the culture that parents should be solely responsible for raising their children, that culture is less likely to provide resources to help parents. This, in turn, affects the structures in which the child functions. The parents' ability or inability to carry out that responsibility toward their child within the context of the child's microsystem is likewise affected

\section{The Chronosystem}

A chronosystem encompasses change or consistency over time not only in the characteristic of the person but also of the environment in which that person lives. This system encompasses the dimension of time as it relates to a child's environments (Darling 2007). Elements within this system can be either external, such as the timing of a parent's death, or internal, such as the physiological changes that occur with the aging of a child. As children get older, they may react differently to environmental changes and may be more able to determine how that change will influence the child' development.(Berk, 2009)

Mothering is within the dynamics of cultural influence and the impact of concentric circles in the ecosystems as explained by the above authors in the preceding paragraphs. The child remains in the first circle while the mother is in all the five but is affected by every layer. As the mother functions in these circles she also interacts with the child from and within many layers of multiple contexts. Out of all the massive interactions cognition develops within layers of multiple contexts.

Child development is made up of all the processes and changes that take place in a child from birth to dearth. Vygotsky, (1978) defined child development as a product of social interactions, where culture is the main determinant of what the child will become. His theory describes children in an apprenticeship role with parents mentoring them through developmental tasks. He used the processes of scaffolding and mentorship by the significant cultural other to explain how cultural experiences are drivers for development.

Most theories of child development specialise in different domains of development, namely emotional, cognitive, social and physical but this theory does not have stages. Piaget's stages of development are infancy, early childhood, late childhood and adolescence. According to his theory a six year old is at the beginning of middle childhood. Bronfenbrenner's theory depicts a developing child as a product of interacting spheres of life representing concentric circles of life through daily life events of a child. The theory shows multi-dimensional and multi directional nature of growth in the context of the family and society. In this study there is only one participant but circumstances of development are many and varied. They impact on the growth of the child from all angles. Each interviewed adult and child represented and angle of the impact of the cyclic multi layered environmental situations. The focus of the study is on the mother child interaction in a given culture which goes through all of the contexts as depicted by the theoretical spheres of life.

\section{THE STAGES OF CHILD DEVELOPMENT IN SETSWANA CULTURE AND BRONFENBRENNER'S ECOLOGICAL SYSTEM THEORY.}

The theory offers invaluable concept and insight of how growth takes place. It gives comprehension of the mother and child's relationship. Setswana culture delineates cultural development stages which are closely observed as the child grows for the proper fitment in the 
society. The following section shows how the developing child moves through the stages within the cultural context provided by multiple contexts defined in the theory section above

\section{Botsetsi stage: Pre-social stage and the microsystem}

Botsetsi is basically an attachment stage. This is an important stage in parent-child relationships. The stage runs from zero to six months. Shapera (1970).It involves the dynamic and complex patterns of sensitive mutual understandings and interactions between the infant and the mother. For instance the mothers speaks, sings to their infants sing even though they know that babies cannot yet understand language. Infants reacts to these activities with joy. Family interactions are directed by the mother. As Coburn, Crnic \& Ross put it "when interactions with caregivers fall out of attunement by becoming mistimed or mismatched, children and parents both experience distress, the mother works very hard to bring joy to the family and Infant. Attunement is characterized by correspondences in biological, affective, cognitive, and behavioural domains. (Coburn, Crnic \& Ross (2015)

Mothers make sure that all domains develop in tune with natures' timing (Coburn, Crnic, \& Ross (2015) It has been observed by previous researchers that mothering varies from culture to culture (Bornstein, 2013;Bugental \& Happaney, 2000; Chao \&Tseng, 2002, Bugental \& Shennum ,1984). Mothering starts at the Botsetsi period. That is the period between the day the baby was born and 6 months. As soon as the child arrives from hospital mother and child are confined to a designated room or hut where almost no one else is allowed inside except the chosen old female adults. The mother remains in isolation with the baby, being on special diet and special health care for at least two months or maximum of six months. (Shapera, 1970). From a cultural perspective the Botsetsi practice protects the new child from diseases and bad people, it also gives the mother to heal and recover from the effects of childbirth.

It serves as a window of opportunity for the mother and the child to get to know each other. It is a societal belief that a child is capable of learning in the first few days of his life, but his adaptive capabilities are deemed very poor. The mother is expected to adapt her behaviour first in order to help the infant to adjust to the new environment. She is also expected to facilitate the infant's cognitive development by equipping the nursery with all kinds of stimuli and challenges. The mother directs the infant's attention to all that the baby needs to see, smell touch, taste, and hear. She also encourages skin to skin contact by having her breast ready in loose or easy to remove clothes.

During breast feeding the mother keeps close eye contact and may sing for the baby or just talk to the new born. The mother monitors feeding, waking, changing diapers and clothes. She also controls bathing times. Both the mother and child grow fond of each other and become reluctant to part when it is time to end the confinement. The elements of love, touch, and fondling, tender care are abundant at this stage of mothering. The family provides care, love security and good mood in the home contributes to the infants happiness and good life. On average, mothers spend between 85 to 100 per cent more time than family do in direct one-toone interaction with the baby at this stage. Mothers always stand up for their children.

There is story that goes from generation to generation in oral literature that states that two women were sleeping in a hut. They both had new borns. One of them got drunk one night and rolled over her infant and killed it during sleep. When she woke up she switched her dead baby with the life baby of her roommate. The two women went to resolve this matter at the chief's court. The judgement was that the child should be cut in half so that both women can share the child. The real mother replied that the drunkard woman can have that child rather than see him killed. The woman stood up for her child and was given to her.Culturaly Batswana mothers 
live for their children. The botsetsi stage gives the opportunity to train their children cognitively by their actions. Cognition is highly regarded in Setswana culture, everyone wants an intelligent child. (ngwana yo o botlhale). If the child turns out average it is the mother's fault.

\section{Ngwana yo o fatlhogang :The inclusion stage for family participation and Mesosystem. Social apprenticeship in early childhood.}

This layer allows the mother and family to interact with the child. The stage is equivalent to early childhood. The child's experiences include interactions with two microsystems, it could be working together as the whole family, sharing the child's education activities. The mesosystem layer may include home education experience and school experiences. The experiences could also be tribal education and church activities. The child is a player in both systems. Depending on the tribe of the mother, after three to six months of confinement, husband ,mother, and family go back to their normal life. They educate the child together under the guidance of cultural scripts of raising children.

For instance, after the Botsetsi period, the child's sleeping, waking, feeding, behaviours are patterned in accordance with the requirements of the household and the patterns are reinforced by the mother. The child exhibits a set of characteristics that helps the mother to decide what actions to take in order to facilitate a desired outcome of the interaction. Eventually this carefully conducted interaction develops into a unique bond between the mother father and family. From as early as four weeks the mother cues the child's responses to be different to father, siblings, and strangers respectively. The mother directs fitment into the two micro systems. Here the child is socialised by the any two systems put together to function and fit in the society.

\section{Ngwana yo o fatlhogileng. Late childhood and the Exosystem.}

Cultural roles of mothering in Botswana involve a life-long process consisting of many complex structures relating to the level of the child's maturity. The mixture of culture and the ecosystem's create the growth pathways for children.(Weisner,2002)The Botsetsi stage leads to the the early childhood stage where the mother now interacts with extended family, the neighbours and the community. This is a stage where the Exosystem works .It is a stage of awakening the mind of the child. (Berk,2004) It is a space of involving a larger sector of the community. The larger the social system the more the child does not function directly in it. This complex layer impacts the child's development by interacting with some structure in the microsystem vicariously. (Berk, 2017;Bornstein, 2013). Community-based family rules, wealth, health and resources impact on the development of the child as ecosystems. Though the child may not be directly involved at this stage it is a window that lets in the economic status of the family to break or build the child's future in terms of functionality and fitment in the society.

\section{Makawana le Makgarejwana:Adolecence and The Macrosystems}

At the age of six to six and half years., both the mother and the child continue to mutually regulates each other's behaviour along the long journey of life-span. Batswana mothers promote independence of the child but never quit the job of discipline and caring up to their last day on earth. At this stage of teenage, children are trained in cultural values, customs, and laws (Berk, 2017). The effects of larger principles defined by the Macrosystems have an influence in the three previous stages. This stage is beyond the scope of the study as its start from thirteen years to nineteen years 


\section{The Chronosystem}

The chronosystem encompasses change or consistency over time not only in the characteristic of the person but also of the environment in which that person lives. Here the the mother conducts cognitive development training for the child to face problems of the world such as death, trauma and and incurable diseases. The quality of parenting one receives during childhood has lasting effects on health and well-being. For example Bornstein,(2013) observed that cultural norms become manifest in the mental health / cognition of children through parenting.The multi-layered theory, helps parents to provide quality Parent to child relationship.

Research suggests that views of parent-child relationships remain relatively consistent from teenage to adulthood (Rossi \& Rossi,1990).The role of mothering in Botswana is very dominant in the overall duty of child development. In this study the author examined the life experiences of one child in detail.Parents acculturate children by preparing them for the physical, psychosocial, and educational situations that are characteristic of their specific culture. Cross-cultural comparisons show that virtually all aspects of parenting children are informed by culture. (Bornstein,2013). However there are ethnic variations in parenting for different tribes in Setswana culture. (Lansford, Bornstein, Dodge, Skinner, Putnick, DeaterDeckard 2011).

\section{METHODOLOGY}

Research design. The research design is case study

\section{Population and sample selection.}

Three Dikgotla (neighbourhoods)were chosen as the population. After surveying the area for two weeks the researcher and assistants found a suitable home for the study.

\section{Participants.}

There is only one participant studied. The participant was recruited by surveying the chosen neighbourhoods where a six year old boy was chosen with the criteria that he met the age and had two loving parents, a big extended family and a large neighbourhood, the research site was Manaledi village in Tswapong area

\section{Research questions}

1. Is there a relationship between a mother's cultural role and children's cognitive development

2. What are the father's attributes for cultural role of child rearing

3. What is the quality of the relationship between the child and the family and the community.

4. Who has the last say in the family about how children should be raised?

\section{Data collection}

Participant observations, interviews, self-reports, retrospective reports of the quality of life were conducted. The parents, extended family, elders in the community gave verbal reports about quality of life and how it affects the growing children in general and specially the boy in the study

\section{Data Analysis}

Qualitative data analysis provides a method for categorizing and organizing the subtleties of everyday social phenomena in a meaningful way. Data analysis started on the onset of field work to help recruit participants. There was a continuum between data collection, data 
description, and data interpretation (Kvale, 1996). As data were analysed, an avenue for identifying any gaps in the data collection arose. It lead to further inquiry and improvement of the interview guide and observation form. According to Bogdan and Biklen (2003), data analysis is defined as working with data, and organizing and breaking data into manageable units to find meaning, patterns and themes.

At the end of data collection the team started by organizing it, breaking it into manageable units, grouping these units into patterns, and themes in order to make sense out of the data. The analysis was guided by this procedure till the end of analysis. Transcripts from recorded interviews and field notes were analysed for research themes. First, the researchers familiarised themselves with the data, The integrity of data was checked through repeated reading of transcripts and field notes. This led to the understanding of depth and breadth of the content.

The data was then re- organised to identify commonalities, differences and patterns across the data, with higher order themes subsequently identified. Each theme was considered, not only in the context of the individual theme itself but how it related to the overall picture painted within the data. In this case study, the researcher collected detailed information about the participant from home ( 8 adults and 5 children) from extended family ( 40 adults and 150 older children) immediate neighbourhood (kgotla) (400 adults and older children), the next close neighbourhood (200adults and children) the furthest neighbourhood 140 adults and children, school five(5) students and five 5(teachers). An advantage of case studies is that they give very detailed information, which is sometimes very unique and interesting. That is the reason why for one child many people had to attest for the many aspects of his integration with them within the physical, spiritual and social realms.

\section{Procedure.}

During the time of the study institutional review boards did not exist in the country. The researcher obtained the research permit from the office of the president as was the practice. The study was approved in the ministry of education. After approval letters were distributed to the community soliciting permission to participate in the study at a village 450 kilometres from the university sponsoring the study. Three neighbourhoods and the school concerted and summited 1,850 consent letters, out of this number only 1000 community members connected to the child were interviewed. As the letters were collected we observed home status of households in the chosen neighbourhoods. Finally a home for research was identified. It was explained to the household and close neighbours how the study was going to work. After that the research assistants and the researcher started working . Research assistants contacted interested parents and set interview schedules with them until the target number of 900 people was reached. Where data was unclear we interviewed extra 53 elderly people. Total duration of the study was 24 weeks.

\section{FINDINGS \\ Research question one: Is there a relationship between a mother's cultural role and children's cognitive development.}

The results revealed that there is a relationship between the mother's cultural role and cognitive development. A strong bond between the child and the mother starts at the Botsetsi stage. This bond drives the development of the child emotionally, socially, physically and mentally. As the child grows, the mother uses the support of emotions, social support, physical growth to build cognitive development at each stage of development. She test the cognitive maturity with traditional cognitive tests such as developmental tasks and oral tradition literature, typically proverbs,reedles and moral stories. by means of successful resolution of 
problems or performance of developmental tasks. These tasks are typically defined by the culture, Havighust, (1953).The bond also leads to a systematic attainment and maintenance of contact between mother and child throughout the life span. Contact in turn reinforce development skills. The mother continues to train the child's cognitive development through apprenticeship.

The Setswana culture demands an intelligent child from the parents. For example comments like (so and so's child is rude and useless, she is not intelligent, her mother did not teach her anything) were uttered during interviews. The natural affection of the mother and concern for survival, success and desire to bring the discovery of the beauty inside to the outside, driven by BOTHO,(BOTHO is the cultural philosophy that means absolute goodness, love, purity, being human and just.) leads to cognitive development. Her parenting is delivered in cognitions expressed in her cultural practices.

Beyond the mother the society has cultural scripts that include developmental tasks. which are used to determine the maturity of cognitive development (see the appendix2).it is therefore the continuing task of parents to enculturate children by preparing them for the physical, psychosocial, and educational situations that are characteristic of their specific culture, with the mother at the center stage. One observation that was beyond the authors' understanding was that, the mother sang to the child before doing school homework task. She said that it pacifies the child and make him think deep in a logical way. She also explained that in their culture music is medicine for the brain so the song activates the brain to release the right answers. This seemed strange but the child was excelling at school. It reminded the author of a story in the Bible where King Solomon was mad. For him to be at peace a young sheperd boy from a small village played a traditional piano for him.

\section{Research question two: What are the father's attributes for cultural role of child rearing}

Mothers and fathers have individually unique and mutually interactive contributions to children's development. The father had unique ways of boosting the boy's self-esteem. He provided sociocultural and family values that shaped the child's attitudes towards being a strong and good male person at home and in the society. He exhibited a father's traditional, authoritarian role which is a culture-cantered attribute. He organized the child's activities leading to security measures and leadership. He applied discipline activities more than the mother. The father also implemented punishment for major transgressions. Most of the time the parents worked together for the good development of the child. The mother had more attributes and was more power than the father in giving directives and organizing the child's life activities.

\section{Research question three: What is the quality of the relationship between the child and the family and the community?}

The participant's name was Onneetse. The name means God has given me this child. Onneetse had high quality relationship in every circle of his environment. At school he had many good friends, most of his cohort admired him and felt empowered around him. He had a great sense of humour, especially when plying sports. He was flexible and agreed to do whatever the coach wants him to do. He seemed to do everything with joy and care. He was cautious, good time keeper, a role model to other students. He was very sensitive to other student's emotional, physical space and honoured the boundaries. In class he was an A star student. All his teachers spoke well about him. All the parents we interviewed about his family had nothing but praise for the boy. The preacher at his church described him as an angel sent from above. He also praised the parents. For a child that young he had very quality relationships. Neighbours wished to have a child like him. At the time of the study his grandmother died, he grieved 
deeply and missed school for three days. He showed affection towards the late grandmother and mourned like a grownup. Normally children of his age do not understand the loss and permanency that comes with dearth.

\section{Research question four: Who has the last say in the family about how children should be raised?}

The grand parents as custodians and monuments of culture controlled the way things were to be done including how children should be raised. The parents followed cultural scripts to give good advice. They believed that much as culture dictates what language the child should speak, culture will also prescribe cognitive, emotional, physical and social development. Vygotsky's theory support this line of thought, (Vygotsky,1978). The elderly keep order and maintains the traditional way of living. But the parents of the children have more power and influence in directing the children to the village culture.

\section{DISCUSSION}

Every culture promotes unique ways of acclimatising their young to its requirements, including ecology. Bronfenbrenner's theory depicts how ecological systems impacts traditions that control childrearing practices all over the world. Literature on parenting has revealed childrearing practices as fundamental across cultures. The cultural contexts of parenthood and childhood are therefore increasingly researched. In the studies reviewed for this article $80 \%$ of them recorded the position of mothers as leaders in child care. (Berk,2018;Baker,Fenning\&Crnic,2011;Bombi,Pastarelli,Lansford,Bacchini,Giunta,Miranda \& Zeli (2011; Chao \& Tseng, 2002). The many articles revealed that mothers have a unique role in child development. The influence of the mother on children's cognitive development was overwhelmly supported by literature. It was described as unequivocally principal to child development (Bornstein,2013; Carneiro P, Meghir C, Parey M Kovess-Masfety, Husky, Keyes, Hamilton, Pez, Bitfoi, Carta, Goelitz, Kuijpers, Otten, Lesinskiene, Mihova(2016); Ross, 2015; Bornstein,2013). Cross-cultural surveys attest to the primacy of maternal caregiving. The role of mothers socialization in shaping cognition and children's developmental outcomes is of universal significance. However, as with the majority of research on other psychological phenomena, studies in this area have largely been conducted in Western countries, particularly the United States, in the country where this study took place there are bits and pieces here and there. It is therefore important for researchers to take the challenge and examine mothers' and fathers' parenting practice, in many different cultures. The impact of culture has consequences for the children's cognition development. It would be beneficial to carry out more research in order to create a more comprehensive understanding of cognition and culture from varied cultures. This would improve the nurturing of children's mental health and cognitive development. Literature has revealed that the happier the child is, the higher the quality of relationships with the mother, the family and community, the higher the quality of the relationship the child is likely to boost intelligence a balanced life, a pleasant personality with less chances to be stressed emotional mentally and socially.

\section{CONCLUSIONS}

Culture influences some parenting cognitions and practices and, in turn impacts on child's cognitive development. This observation is supported by literature. (Coburn, Crnic , \& Ross, 2015; Keyes, Susser, Pilowsky, Hamilton , Bitfoi , Goelitz, Kuijpers , Lesinskiene, Mihova, Otten, Kovess, Bornstein, 2013; Ellingsen, et al.2013; Baker, Fenning, R. \& Crnic, 2011;Lee, and Bowen, 2006; Adeyemi, \& Adeyinka,2002; Arthur,1998 Losike-Sedimo,1996)

Cultural explanations for cognition and and cognitive development have been presented to account for the findings of this study. Specifically the sociocultural value 
(Bornstein,2012,2010,204) that foster children's cognitive development. Mothers provide childhood experiences and maneuver the environments paths for children's development to contribute to child cognitive development (Carneiro, Meghir, Parey,2012; Pleck, 2012).The study has shown that children grow in multiple contexts. It also revealed that mother's cultural role does contribute to cognitive development (Bornstein,2013). In Setswana culture the mother orchestrates the cognition development through her mothering techniques (Muir \& Bohr, 2014, Nsamenang, 2014;Losike- Sedimo, 1996); adults who report having had high quality relationships with their parents during childhood have better overall mental health and are and decreased risk for mental disorders compared to those who report low parental relationship quality results indicate that mother-child relationship father to child and child to school personnel, classmates and friends was of high quality.

\section{LIMITATIONS}

This study has limitation due to the research method. Only one unit was studied in detail. That limits the application of results to a larger population. A disadvantage of case studies is that they are very subjective, both because they are only on an individual unit and also because of the researcher's possible bias. Another problem is that it is hard to generalise from case studies, as one unit to a bigger population. In addition they provide a whole hundred by hundred square miles of data which is impossible to use all of it.

\section{RECOMMENDATIONS}

More effort should be made to carry out research ion culture and cognitive development in research institutions. 2. More studies from varied cultures on culture and child development is needed. More studies using complex study method are needed to study culture and cognition. As indicated in the literature, it is imperative to learn more about culture and parenting, so that scientists, educators, and practitioners can effectively enhance child development with best techniques of parenting

\section{References}

Adeyemi, M. B. \& Adeyinka, A. A. (2002). Some key issues in African traditional education.

McGill journal of education, 37 (2), 223-240Alampay, L. P. \& Jocson, R.M. (2011).Attributions and Attitudes of Mothers and Fathers in

Arthur, J. (1998). Institutional practices and the cultural construction of primary school teaching in Botswana. Comparative education, 34 (3), 313-332.

Azuma, H. (1986). Why study child development in Japan? In Stevenson, H., Azuma, H., \&

Hakuta, K, (eds.), Child development and education in Japan. New York: Freeman. p. 3-12

Berk, L.E. (2017). Development Through the Lifespan. Pearson Education.

Berk, L. E. (2009) Development Through the Lifespan (5th Ed.). Pearson Education.

Berk, L. E. (2004) Development through the life span. (3 $3^{\text {rd }}$ Ed.). Boston: Allyn and Bacon.

Berk, L. E. (2004). Awakening children's minds. Oxford university press.

Berk, L. E. (2002) Infants, Children, and Adolescents. Boston :Allyn and Bacon:

Berk, L. E. (2000). Child Development (5th Ed.). Boston :Allyn and Bacon

Baker, J., Fenning., R., \& Crnic, K. (2011). Emotion Socialization by Mothers and

Fathers: Coherence among behaviours and associations with parent attitudes and children's social competence. Social Development, (20), 412-430

Belsky, J. (1984). The determinants of parenting: A process model. Child Development,(55),83-96

Bornstein, M . H. (2013). Parenting and child mental health: a cross-cultural perspective. World psychiatry, 12(3), $255-265$ 
Bornstein, M. H., Putnick, D. L., Lansford J. E., Pastorelli, C., Skinner, A.T., Sorbring, E., Tapanya, S., Tirado, L . M., Zelli, A., Alampay, L. P., Al-Hassan, S .M., Bacchini, D., Bombi, A . S., Chang, L., Deater-Deckard, K., Di Giunta, L., Dodge, K.A., Malone, P. S., \& Oburu, P. (2015). Mother and father socially desirable responding in nine countries: Two kinds of agreement and relations to parenting self-reports. International Journal of Psychology, 50 (3),17485.

Bornstein, M. H.( 2002). Handbook of parenting: Parental beliefs and cognitions: he dynamic Status and social conditions of parenting. 2nd ed. Mahwah: Erlbaum; 2002. pp. 485-508

Bornstein, M.H., Putnick, D. L., \& Lansford J.E. (2011). Parenting Attributions and Attitudes in Cross-Cultural Perspective, Parent Sci Pract,11(2), 214-237.

Bombi , A. S., Pastorelli, C., Bacchini, D., Di Giunta, L., Miranda, M. C.,\& Zelli., A. (2011). Attributions and Attitudes of Mothers and Fathers in Italy. Parent Science Practice, 11 (2-3), 129 -141

Bronfenbrenner, U., \& Morris, P. A. (2006).The bio ecological model of human development. In Lerner, R.M, Damon, W. (eds.), Handbook of child psychology, Vol. 1, Theoretical models of human development. New York: Wiley; 2006. pp. 793

Bugental, D.B \& Happaney, K. (2000). Parent-child interaction as a power contest. Journal of applied developmental psychology,(21), 267-282.

Bronfenbrenner, U. (1979). The ecology of human development. Cambridge: Harvard University Press:

Chao, R. \& Tseng, V. (2002). Parenting of Asians. In M. H. Bornstein. Handbook of parenting. Vol. 4. , NJ: Erlbaum.

Carneiro P, Meghir C, Parey M. (2013), Maternal education, home environments, and the development the development of children and adolescents. Journal of European Economic, Association.(11)123-60.

Coburn, S.S., Crnic, K. A. \& Ross, E. C. (2015). Mother-infant dyadic state behaviour: dynamic systems in the context of risk. Infant and child development, 24 (3), 274 - 297.

Darling, N. (2007). Ecological Systems Theory: The person in the centre of the circles. Research in Human Development, 4(3-4), 203-217.

Farver, J. M. \& Howes, C. (1993).Cultural Differences in American and Mexican Mother-Child Pretend Play MerrillPalmer Quarterly, 39 (3), 344-358

Giuliana, P., Primi, C.,Tarchi, C., \& Bigozzi, L. (2017). Mental state talk structure in children's narratives: A cluster analysis, Child development,(2017) 1-7.

Kendrick, A. D., Watson, M., \& Shaw, I. (2015). Maternal perceptions of supervision in pre-school-aged children: a qualitative approach to understanding differences between families living in affluent and disadvantaged areas, Primary Health Care Research \& Development, 16, (4), 346-355.

Keyes, K . M., Susser, E., Pilowsky., D .J, Hamilton, A., Bitfoi, A., Goelitz, D., Kuijpers, R. C., Lesinskiene, S., Mihova, Z., Otten R., Kovess, V. (2014). Unintentional injuries among European schoolchildren. PMC, (67 ), 182 - 188

Kovess-Masfety, V. Husky, M . M., Keyes, K., Hamilton, A., Pez, O., Bitfoi, A., Carta, M.G., Goelitz, D., Kuijpers, R., Otten, R., Koç, C., Lesinskiene, S., Mihova, Z. (2016). Comparing the prevalence of mental health problems in children 6-11 across Europe, Social psychiatry and psychiatric epidemiology,51(8),1093-103.

Kvale, S,(1996). An introduction to qualitative research interviewing .1st Edition. Sage publication.

Lansford, J.E., Bornstein, M.H., Dodge, K.A., Skinner, A.T., Putnick, D.L., Deater-Deckard, K. (2011). Attributions and attitudes of mothers and fathers in the United States. Parent Sci Pract,11(2-3),199-213.

Lee, J. \& Bowen, N. (2006). Parent involvement, cultural capital, and the achievement gap among elementary school children. American Educational Research Journal, 43, 193-218

Losike-Sedimo, N. C. (1996). Cognitive development and child rearing practices in Botswana: a challenge for quality education The journal of Special Education Research Review, 1(1), 7 - 22.

Muir, N. \& Bohr, Y. (2014). Contemporary practice of traditional aboriginal child rearing: A Review. First Peoples Child \& Family Review , 9, (1) , 67 - 79.

Nsamenang, A. B. (2014). Early childhood care and education working papers series. Implications of research on indigenous African child development and socialization. United Nations Educational, Scientific and Cultural Organization.

Pleck J. (2012).Integrating father involvement in parenting research. Parent Science Practice. (12), 243-53. 
Patel, V. Sumathipala, A. (2001). International representation in psychiatric literature: survey of six leading journals. British Journal of Psychiatry.

Rossi, A.S., \& Rossi, P.H. (1990). Of human bonding: Parent-child relations across the life course. New York: Aldine de Gruyter.

Shapera, I. (1970). A Handbook of Tswana Law and Custom London: Oxford University Express

Shears J, Robinson J. Fathering attitudes and practices: Influences on children's development. Child Care in Practice.(2005 (11),

Schaffer, H.R. (1977). Mothering. London: Fontana; Cambridge

Sherr, K. J. Roberts, I \& M. Tomlinson. (2017). Parenting, the other oldest profession in the World, a crosssectional study of parenting and child outcomes in South Africa and Malawi, Health Psychology and Behavioural Medicine, 5 (1), 145-165.

Sigel, I .E., McGillicuddy-De Lisi. A.V. (2002) Parental beliefs and cognitions: the dynamic Status and social conditions of parenting. 2nd ed. Mahwah: Erlbaum. pp. 485-508.Stevenson \& Crnic, (2015). Fathering attitudes and practices: Influences on children's development. Child Care in Practice ,11 (1), 63- 79.

Wood, E. E.\& Kennison, S.M. (2017).Young children's risk-taking: Mothers' authoritarian parenting predicts risktaking by daughters but not sons. The health consequences of child mental health problems and parenting styles change. Psychological Review, (84), 191-215.

Weisner, T.S. (2002). Ecocultural understanding of children's developmental pathways. Human Dev,45 (4),275 281

Sesma, A, \& Williamson, I. (2001). Mothers' conceptions of child competence in contexts of poverty: The Philippines, St. Vincent, and the United States. International Journal of Behavioural Development. 25:438-443

Vygotsky, L.S. (1978), Mind in Society, Harvard UP, Cambridge.

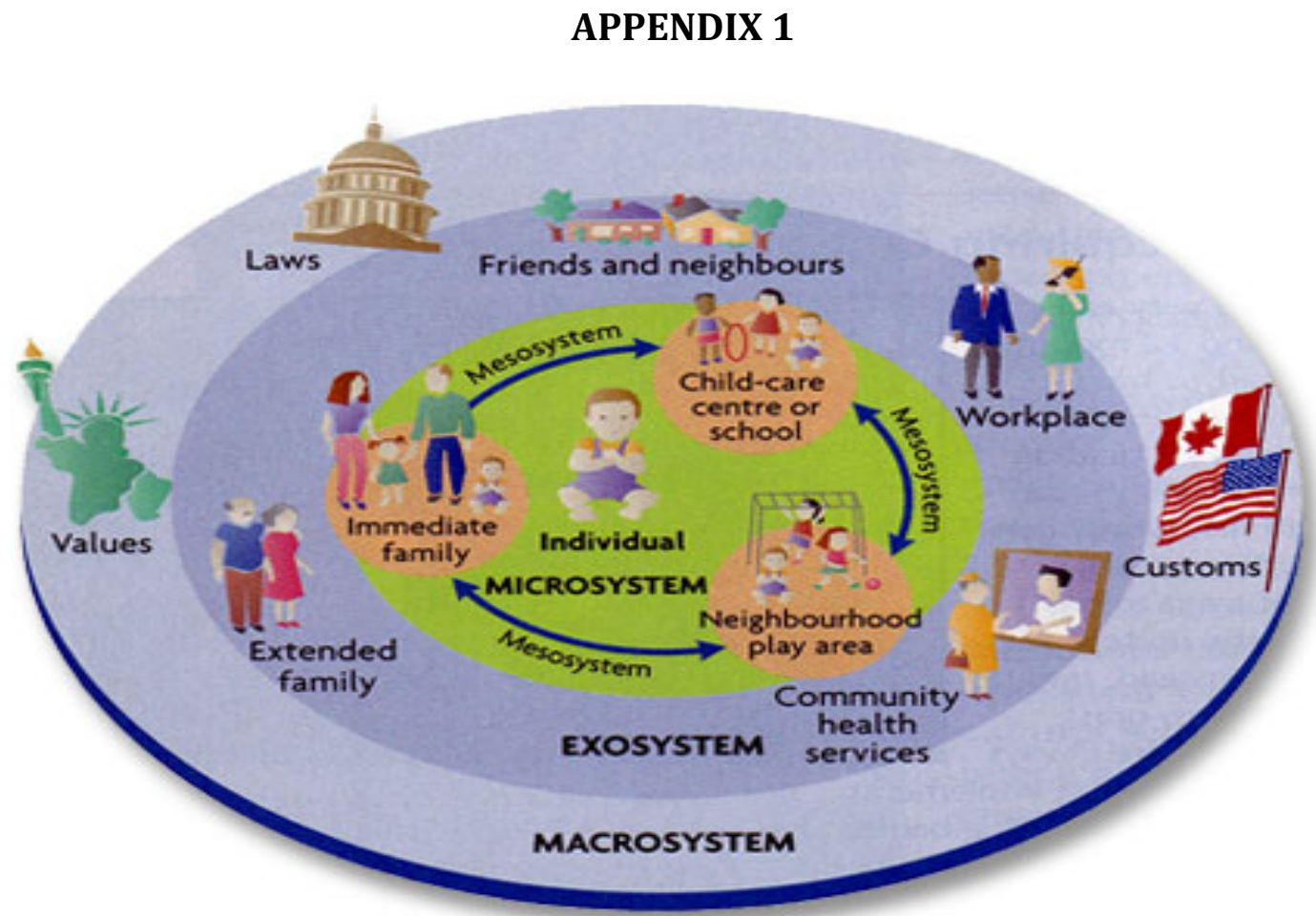

Figure 1. Bronfenbrenner's ecological systems theory (in Berk \& Roberts, 2009, p. 28) 


\section{APPENDIX 2}

\section{CULTURAL DEVELOPMENTANTAL TASKS FOR BATSWANA CHILDREN}

Teaching of cultural tasks to children develops them physically, intellectually, emotionally, psychosexually, socially, familial development, educationally, vocational and spiritually. Girls Tasks

$6-19$ years

Go phepahatsa mo lwapeng

House keeping

Gothuga kana go setla Milling soghum or Corn

Go apaa

Cooking daily meals with multiple methods

Go ya nokeng

Fetching water and conserving it

Go disa- Herding animals and taking care of them

Go apaa Cooking

Go duba Mmu making a mud mix and partaking in building a home

Go tsaya karolo mo temong. Knowing how to plough and take part in all agricultural activities

Go tlhokomela bo monnao. Knowing how to take care of one's siblings

Go ya Bojale Going to traditional initiation schools

Go nna le mophato. To belong to a child development stage group

Go tlhokomela monna le bana - Caring for children and men
Boys' Tasks 6- 19 years

Go disa Herding small stock

Herding calves

Herding cattle

Go nosa.

taking domestic aninmals to the river to drink

Go tshwara mogoma - to keep the plough

in position while the oxen team pulls

Go tshwara teu - To lead a team of cattle that are pulling the plough

Go lema To plough

Go rema dikgong, ditlhare, go aga lesaka, go rema tshimo. Cutting trees to make production structures

Go thibelela.

Clearing space to build a new home

Go tsaya karolo mo temong. Knowing how to plough and take part in all agricultural activities

Go ya Bogwera. Going to traditional initiation schools

Bosole, joining the army

Go tlhabanela setshaba being a soldier

Go tlhokomela mosadi le bana. Providing for the family. Farming/hunting game and fowl 